Canadian

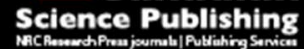

Canadian Journal of Chemistry Revue canadienne de chimie

\title{
Dye rejection membranes prepared from oxidized graphite particles
}

\begin{tabular}{|r|l|}
\hline Journal: & Canadian Journal of Chemistry \\
\hline Manuscript ID & cjc-2016-0628.R1 \\
\hline Manuscript Type: & Article \\
\hline Date Submitted by the Author: & O2-Feb-2017 \\
\hline Complete List of Authors: & $\begin{array}{l}\text { Colomba, Anastasia; The University of Western Ontario, Department of } \\
\text { Chemistry } \\
\text { Biesinger, Mark; The University of Western Ontario, Surface Science } \\
\text { Western } \\
\text { Divigalpitiya, Ranjith; 3M Canada Company } \\
\text { Brandys, Frank; 3M Canada Company } \\
\text { Gilroy, Joe; The University of Western Ontario, Department of Chemistry }\end{array}$ \\
\hline Keyword: & $\begin{array}{l}\text { Materials Characterization, Chemically Modified Graphite, Dye Rejection } \\
\text { Membranes, Carbon-Based Materials, Wastewater Purification }\end{array}$ \\
\hline
\end{tabular}




\section{Dye rejection membranes prepared from oxidized graphite particles}

Anastasia Colomba ${ }^{a}$, Mark C. Biesinger $^{b}$, Ranjith Divigalpitiya ${ }^{c}$, Frank A. Brandys $^{c}$, and Joe B. Gilroy ${ }^{a}$

${ }^{a}$ Department of Chemistry and the Centre for Advanced Materials and Biomaterials Research (CAMBR), The University of Western Ontario, London, Ontario, Canada, N6A 5B7.

${ }^{b}$ Surface Science Western, The University of Western Ontario, London, Ontario, Canada, N6A 5B7.

c3M Canada Company, 1840 Oxford Street East, London, Ontario, Canada, N5V 3R6.

*Corresponding author. E-mail: joe.gilroy@uwo.ca (Joe B. Gilroy) 


\title{
Graphical Abstract
}
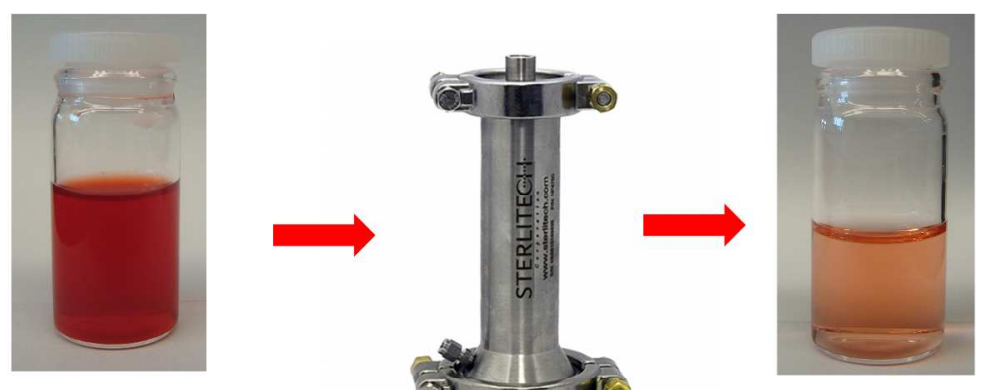

Congo Red

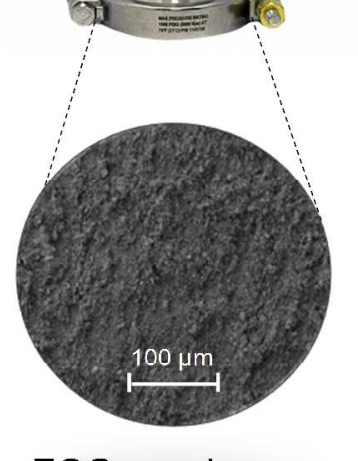

EOG membrane

\begin{abstract}
This article reports the comparison of different chemical methods to produce graphitebased particles with varying degrees of oxidation as well as graphene oxide (GO) and pristine graphite (PG). Detailed physico-chemical characterization of the resulting materials was carried out, highlighting structural differences and variable oxygen content. The particles were then used to produce supported membranes, which were tested for the rejection of three different organic dyes (Rhodamine B, Methyl Blue and Congo Red), and their performance was rationalized in terms of a combination of properties of the membranes and dyes. In particular, membranes produced using edge-oxidized graphite (EOG) showed comparable performance to those derived from GO in the removal of Congo Red, providing a promising alternative to the aforementioned.
\end{abstract}

Keywords: dye rejection membranes; materials characterization; chemically modified graphite; carbon-based materials; waste water purification 


\section{Introduction}

Water purification is one of the fastest growing markets: Boston Consulting Group reported a demand of $\$ 47.7$ billion for products related to waste water treatment in the top 40 national markets in 2012, with an estimated compound annual growth rate of $10.2 \%$ for the period between 2014 and 2019. ${ }^{1}$ Recent advances in nanotechnology offer opportunities to develop the next-generation of water supply systems, with applications ranging from adsorption to photocatalysis and membrane filtration systems. ${ }^{2}$ Since the discovery of graphene, there have been numerous studies related to its applications across the physical sciences, health sciences, and engineering. Graphene has been widely studied for its electrical properties, transparency and flexibility for energy storage, sensors, electronic devices, polymer composites and many other applications, $^{3-9}$ but it is graphene oxide (GO) that has mainly been studied for filtration applications. $^{10-11} \mathrm{GO}$ is hydrophilic, easy to disperse in water and other solvents and readily undergoes chemical functionalization. ${ }^{12}$ It has been shown that GO or functionalized GO sheets can be stacked to produce high-flux membranes that can effectively be used for pervaporation, ${ }^{13}$ nanofiltration, ${ }^{14}$ ultrafiltration, ${ }^{15}$ microfiltration, ${ }^{16}$ reverse osmosis $^{17}$ and photocatalytic degradation of contaminants. ${ }^{18}$

GO is often produced via the harsh oxidation of graphite through Hummers' method, ${ }^{19}$ with the main drawbacks of introducing severe disruption to the structure of the graphene sheets and the use of high concentrations of hazardous chemicals. More recently, different groups have reported relatively mild conditions for the functionalization of graphite to produce edge-oxidized graphite (EOG), that could then be intercalated or exfoliated into graphene nano-sheets. ${ }^{20-22}$

In this study, we aimed to produce particles derived from graphite with different degrees of oxidation, ranging from mild oxidation to heavily oxidized GO, and compare their physico- 
chemical properties. The particles were then used for the production of supported membranes on a modified nylon substrate by means of a simple vacuum-assisted self-assembly technique. Finally, the rejection of three different organic dyes (Rhodamine B, Methyl Blue, Congo Red) from water in stirred cell experiments was investigated.

\section{Experimental}

\section{Materials}

TIMREX® HSAG300 (PG: $6 \mu \mathrm{m}$ diameter, $300 \mathrm{~m}^{2} / \mathrm{g}$ surface area) was purchased from TIMCAL and used as a starting material. $\mathrm{NaNO}_{3}$ (Anachemica), $\mathrm{KMnO}_{4}$ (Sigma Aldrich), concentrated $\mathrm{H}_{2} \mathrm{SO}_{4}, 70 \% \mathrm{HNO}_{3}$, and $\mathrm{H}_{2} \mathrm{O}_{2}$ (Caledon) were used as reagents without further purification. Methyl Blue, Congo Red (Sigma Aldrich) and Rhodamine B (Alfa Aesar) were used as dyes for the rejection studies. Modified nylon membranes (EF004, average pore diameter $0.04 \mu \mathrm{m})$ were obtained from 3M Canada.

\section{Sample preparation}

Nitric acid oxidized (NAO) particles were prepared following a modified version of the procedure reported by Dalai and co-workers. ${ }^{23} 5.0 \mathrm{~g}$ of HSAG300 were added to $32 \mathrm{~mL}$ of $70 \%$ $\mathrm{HNO}_{3}$. This mixture was refluxed at $35{ }^{\circ} \mathrm{C}$ for $2.5 \mathrm{~h}$ using a reflux condenser connected to a recirculating chiller. A magnetic stirrer was used for mixing during the reflux. The sample was washed with $\mathrm{H}_{2} \mathrm{O}$ to remove residual acid and centrifuged repeatedly (ca. 15 times) at $4500 \mathrm{rpm}$, until the supernatant $\mathrm{pH}$ reached neutrality. The resulting product was dried overnight at $80{ }^{\circ} \mathrm{C}$ to yield $4.8 \mathrm{~g}$ of black powder.

Edge-oxidized graphite was prepared according to the method previously reported by $\mathrm{Wu}$, Zou and co-workers. ${ }^{21} 1.0 \mathrm{~g}$ of graphite was added to $23 \mathrm{~mL}$ of concentrated $\mathrm{H}_{2} \mathrm{SO}_{4}$ and 0.1 $\mathrm{g} \mathrm{NaNO}_{3}$ in an ice bath, and stirred for $10 \mathrm{~min} .0 .8 \mathrm{~g}$ of $\mathrm{KMnO}_{4}$ were then slowly added to the 
solution to maintain the temperature below $20{ }^{\circ} \mathrm{C}$. The mixture was then brought to $35{ }^{\circ} \mathrm{C}$ and stirred for an additional $30 \mathrm{~min}$, followed by the slow addition of $45 \mathrm{~mL} \mathrm{H}_{2} \mathrm{O}$. After $15 \mathrm{~min}, 140$ $\mathrm{mL} \mathrm{H}_{2} \mathrm{O}$ and $7.5 \mathrm{~mL}$ of $30 \% \mathrm{H}_{2} \mathrm{O}_{2}$ were added. The solution was then washed with $\mathrm{H}_{2} \mathrm{O}$ and centrifuged repeatedly ( $c a .15$ times) at $4500 \mathrm{rpm}$, until the supernatant $\mathrm{pH}$ reached neutrality. The resulting product was dried overnight at $80{ }^{\circ} \mathrm{C}$ to yield $1.1 \mathrm{~g}$ of dark grey powder.

Graphene oxide (GO) was produced according to a modified version of Hummers' method. ${ }^{22} 1.0 \mathrm{~g}$ of graphite was added to $100 \mathrm{~mL}$ concentrated $\mathrm{H}_{2} \mathrm{SO}_{4}$ and soaked for $12 \mathrm{~h}$, after which $0.74 \mathrm{~g} \mathrm{NaNO}_{3}$ were added. The mixture was then cooled down in an ice bath and $3.4 \mathrm{~g}$ of $\mathrm{KMnO}_{4}$ were added, followed by stirring for $2 \mathrm{~h}$ in an ice bath and room temperature for 5 days. $5 \mathrm{~mL}$ of $\mathrm{H}_{2} \mathrm{O}$ were then slowly added to the mixture, and after 5 min another addition of $4 \mathrm{~mL}$ and $3 \mathrm{~mL}$ of $30 \% \mathrm{H}_{2} \mathrm{O}_{2}$ was performed. $500 \mathrm{~mL}$ of $\mathrm{H}_{2} \mathrm{O}$ were then added to reduce the viscosity of the mixture. The obtained solution (brown in colour) was then repeatedly washed with $\mathrm{H}_{2} \mathrm{O}$ and centrifuged (ca. 30 times) at $4500 \mathrm{rpm}$, until the supernatant $\mathrm{pH}$ reached neutrality. The resulting product was dried overnight at $80{ }^{\circ} \mathrm{C}$ to yield $0.9 \mathrm{~g}$ of black powder.

\section{Powder characterization methods}

Thermogravimetric analysis (TGA) profiles were obtained using a TA Instrument Q50 TGA and Pt sample pans under a flow of $\mathrm{N}_{2}$. Prior to the run, the temperature was equilibrated at $25^{\circ} \mathrm{C}$ for $1 \mathrm{~min}$ followed by an increase to $1000^{\circ} \mathrm{C}$ at a rate of $10^{\circ} \mathrm{C} / \mathrm{min}$.

Powder X-ray diffraction (PXRD) analyses were conducted from 5-120 (20) using an Inel CPS Powder Diffractometer with $\mathrm{Cu}$ X-ray radiation, equipped with an Inel XRG 3000 generator and Inel CPS 120 detector on an aluminum sample holder. 
Raman spectroscopy was carried out using a Renishaw Invia Raman microscope equipped with a 20× magnification objective and a $633 \mathrm{~nm}$ excitation laser.

Energy-dispersive X-ray (EDX) spectroscopy measurements were carried out using a Hitachi TM-3000 SEM equipped with a Bruker Quantax 70 EDX detector at a 30× magnification and $15 \mathrm{kV}$.

X-ray photoelectron spectroscopy (XPS) was performed on a Kratos AXIS Nova Spectrometer located at Surface Science Western (The University of Western Ontario). All samples were mounted by pressing a thick layer of the sample onto double sided adhesive tape. The Kratos charge neutralizer system was used on all specimens. Survey scan analyses were carried out with an analysis area of $300 \times 700$ microns and a pass energy of $160 \mathrm{eV}$. High resolution analyses were carried out with an analysis area of $300 \times 700$ microns and a pass energy of $20 \mathrm{eV}$. Spectra have been charge corrected to the $\mathrm{C}=\mathrm{C}$ line of the carbon 1 s spectrum (graphitic carbon) set to $284.5 \mathrm{eV}$. Spectra were analysed using CasaXPS software (version 2.3.14).

\section{Membrane preparation and characterization}

Membranes were prepared as follows: a 400 ppm solution of the different samples was prepared and sonicated for $2 \mathrm{~h}$. After this, $100 \mathrm{~mL}$ of the solution were deposited on a $14.6 \mathrm{~cm}^{2}$ disk of porous substrate (modified nylon, average pore diameter $0.04 \mu \mathrm{m}$ ) by vacuum filtration. The membranes were then air dried overnight in a fume hood.

The membranes thicknesses were measured with two different methods: a micrometer (MITUTOYO IP 65 MICROMETER) and by SEM (NanoFabrication Facility, The University of 
Western Ontario). The SEM measurements were carried out on a cross section of the membrane using a LEO (Zeiss) 1540XB FIB/SEM at a 200x magnification and $5 \mathrm{kV}$ EHT voltage level.

\section{Dye rejection studies}

Rejection experiments were carried out in a 316 stainless steel stirred cell (Steriltech HP4750) at an operating pressure of 60 psi. Three solutions were prepared: Rhodamine B (50 mg/L), Methyl Blue $(10 \mathrm{mg} / \mathrm{L})$ and Congo Red $(50 \mathrm{mg} / \mathrm{L})$. The experiments were carried out by running seven consecutive filtration cycles and collecting $30 \mathrm{~mL}$ aliquots of each dye solution for each membrane; their concentration was monitored using a Shimadzu UV-1800 UV-vis spectrophotometer at wavelengths of 554, 594 and $498 \mathrm{~nm}$, respectively. The data reported in Fig. 10 were taken from the seventh filtration cycle, chosen as the $\%$ rejection values changed by less than $5 \%$ compared to the sixth filtration cycle, to ensure that the adsorption sites on the surface of the carbon layer were saturated. The data for each of the seven filtration cycles can be found in Fig. S8-S10. The time required to collect the $30 \mathrm{~mL}$ sample was recorded and used to calculate the flux normalized with respect to the surface and pressure as:

$$
\frac{L M H}{\text { bar }}=\frac{\text { Volume }(L)}{\text { Area }\left(m^{2}\right) \cdot \text { Time }(h) \cdot \text { Pressure }(\text { bar })}
$$

\section{Results and discussion}

\section{Powder characterization}

Details of the preparation of oxidized graphitic particles are outlined in the experimental section. Fig. 1 shows thermogravimetric analysis (TGA) data for the four different powder samples. Pristine graphite (PG), used as a control, showed very limited weight loss (about 5\%) in the temperature window studied $\left(25 \rightarrow 1000{ }^{\circ} \mathrm{C}\right)$, while NAO had a total weight loss of about $19 \%$, mostly at temperatures above $600{ }^{\circ} \mathrm{C}$. EOG showed significant weight loss in the $200-300{ }^{\circ} \mathrm{C}$ 
region. This is the region in which carboxylic acid groups and other oxygen-based functionalities are thermally decomposed, ${ }^{24}$ yielding $\mathrm{CO}, \mathrm{CO}_{2}$ and steam, after which no significant weight loss was observed. GO is the only sample that showed significant weight loss at temperatures below $100{ }^{\circ} \mathrm{C}$. Usually, weight loss between $50-120{ }^{\circ} \mathrm{C}$ is attributed to the loss of water molecules trapped within GO sheets. ${ }^{25}$ Analogously to EOG, significant weight loss in the $200-300{ }^{\circ} \mathrm{C}$ region was attributed to the volatilization of oxygen-containing functional groups, while the weight loss at $\mathrm{T}>600{ }^{\circ} \mathrm{C}$ was due to the combustion of the carbon skeleton. ${ }^{26}$

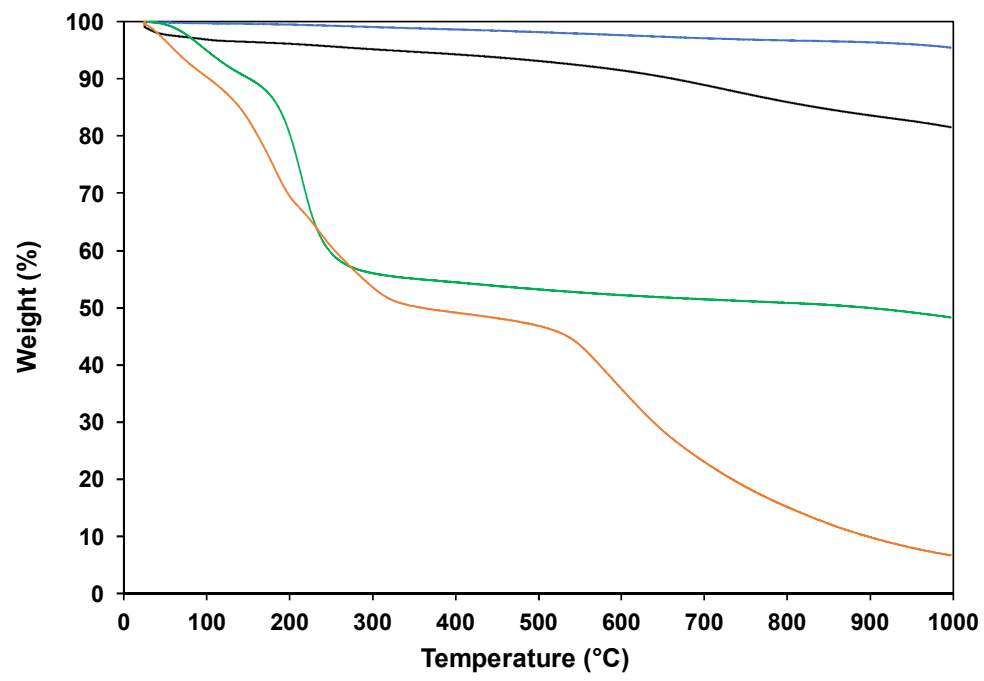

Fig. 1. TGA data for PG (blue), NAO (black), EOG (green) and GO (orange).

The samples were further characterized by PXRD (Fig. 2). PG showed the typical narrow graphitic [002] peak at $26.4^{\circ}$ corresponding to an ideal layered structure with a d-spacing of 0.34 nm. ${ }^{27}$ In NAO, the [002] peak did not show any significant changes. There was an increase in the intensity and sharpening of the [100/101] peak located at $44.0^{\circ}$, associated with a decrease in the average crystallite size, suggesting that, despite the limited differences in the [002] peak between the samples, physical changes are occurring during the oxidation process. ${ }^{28}$ In the case of EOG, 
while the peak location did not change, peak broadening was observed. This is usually attributed to the presence of strain/defects, and could imply that most of the functional groups are located at the edges of the graphitic domain and not in the basal planes, ${ }^{29}$ thus creating a straining effect and preventing efficient stacking of graphene sheets. In the case of GO, the peak shifted to $10.9^{\circ}$, which corresponded to an interlayer distance of about $0.81 \mathrm{~nm}$, due to the presence of water molecules trapped between the hydrophilic GO sheets. ${ }^{11,30}$

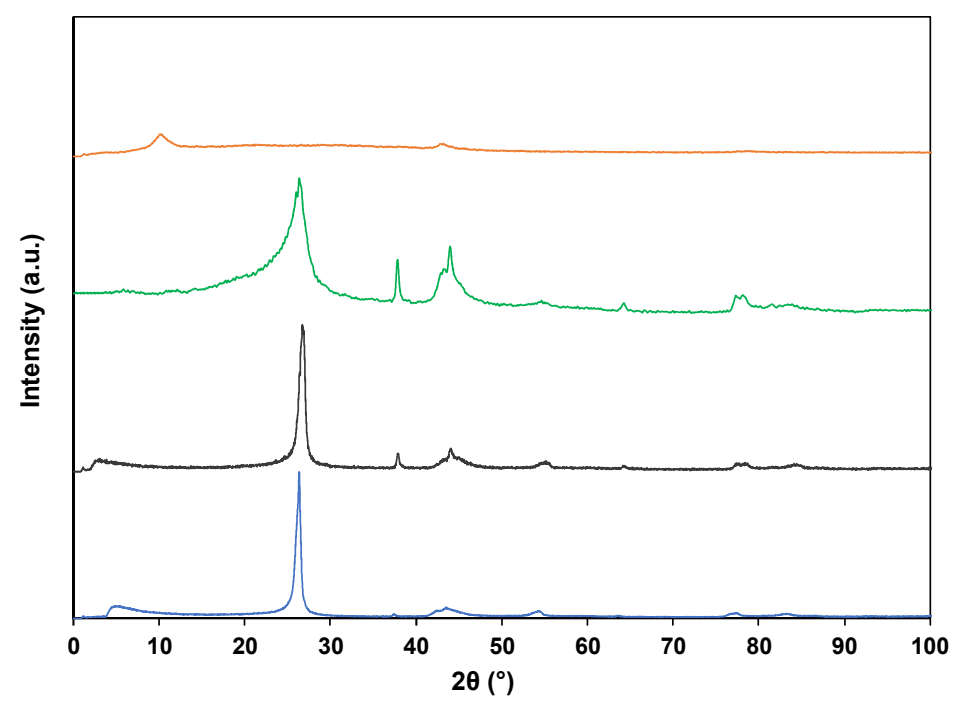

Fig. 2. PXRD data collected for PG (blue), NAO (black), EOG (green) and GO (orange).

In order to further understand the difference between the samples oxidized via different chemical treatments, the oxygen and carbon contents were measured by EDX spectroscopy. The results (Fig. 3) showed that no oxygen was detected in PG, while the oxygen level increased to $9 \%$ for $\mathrm{NAO}$ and $23 \%$ for EOG, up to a maximum of $44 \%$ weight for GO. This correspond to atomic $\mathrm{C} / \mathrm{O}$ ratios of $13.0,4.3$ and 1.7 for $\mathrm{NAO}$, EOG and $\mathrm{GO}$, respectively, which agree well with previously reported values for $\mathrm{EOG}^{21-22}$ and $\mathrm{GO} .^{20,31}$ 


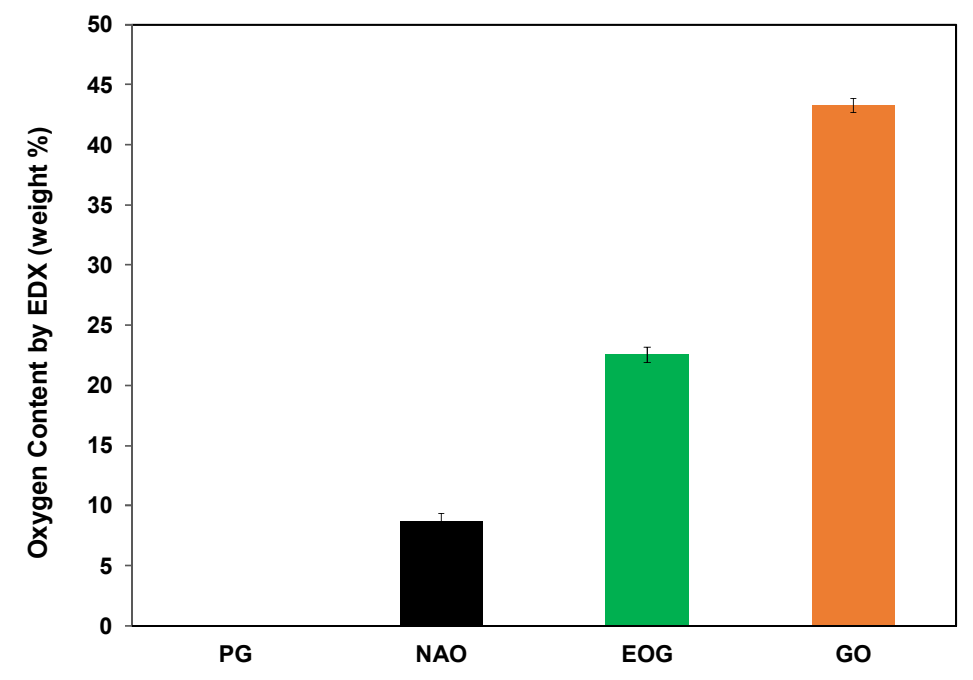

Fig. 3. Oxygen content obtained by EDX spectroscopy for PG, NAO, EOG and GO. Error bars calculated from three replicates.

Oxygen and carbon analysis by XPS (Fig. S1) showed strong $C_{1 \mathrm{~s}}(\sim 284.5 \mathrm{eV})$ and weak $\mathrm{O}_{1 \mathrm{~s}}(\sim 532.0 \mathrm{eV})$ peaks for $\mathrm{PG}$, and an increase in the $\mathrm{O}_{1 \mathrm{~s}}$ peak for $\mathrm{NAO}$, EOG and $\mathrm{GO}$, for which the peak intensity surpassed that of the $C_{1 s}$ peak. The oxygen and carbon contents were in agreement with the values obtained by EDX spectroscopy (Fig. 4). The similar values obtained using these techniques confirmed the uniform oxidation of the corresponding powders and small discrepancies between the two methods may be attributed to chemisorbed oxygen. 


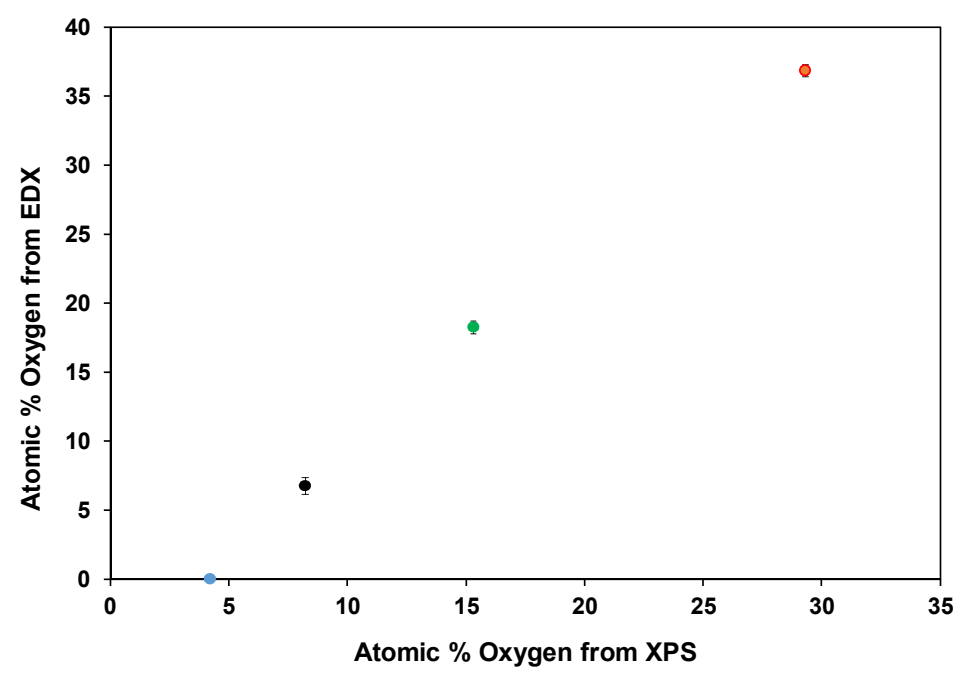

Fig. 4. Comparison between oxygen content values for PG (blue), NAO (black), EOG (green) and GO (orange) obtained by EDX spectroscopy and XPS. Error bars calculated from three replicates.

Due the high surface area of PG, its Raman spectrum (Fig. 5) showed a well-defined D peak, usually absent in highly crystalline graphite samples. The defect-induced D' Raman feature was present as a shoulder of the $\mathrm{G}$ peak. ${ }^{32}$ Progressive red-shifts in both $\mathrm{G}\left(1327-1339 \mathrm{~cm}^{-1}\right)$ and D peaks $\left(1570-1590 \mathrm{~cm}^{-1}\right)$ from the bottom to the top of the graph as a result of increased oxidation levels can be observed. The oxidation process also resulted in increased values of the integrated $\mathrm{I}_{\mathrm{D}} / \mathrm{I}_{\mathrm{G}}$ peak ratio, corresponding to an increased concentration of defects in the planar structure of graphite. ${ }^{33}$ The relationship between the oxygen content and $\mathrm{I}_{\mathrm{D}} / \mathrm{I}_{\mathrm{G}}$ ratio, as shown in Fig. 6, follows a linear trend. The 2D peak $\left(2680 \mathrm{~cm}^{-1}\right)$ is usually associated with the number of graphene layers present and it can be observed that, while it was similar for PG, NAO and EOG, the signal was absent in the case of GO. Rather, smaller intensity $\mathrm{D}+\mathrm{G}$ peaks were observed as a result of the disruption of stacking order associated with the oxidation reaction. ${ }^{32}$ 


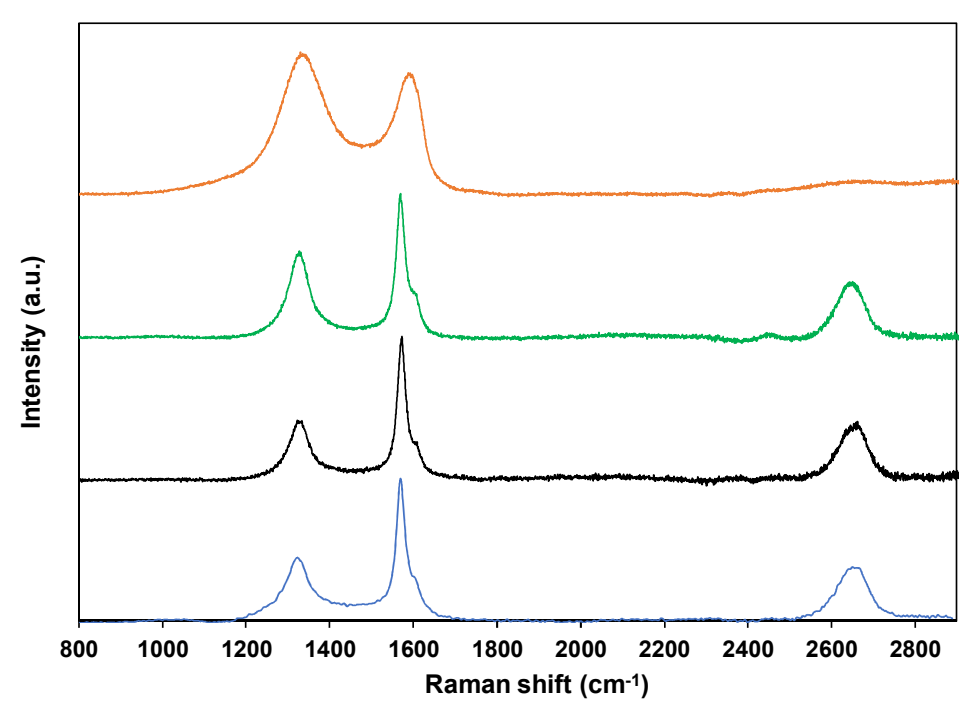

Fig. 5. Raman spectra of PG (blue), NAO (black), EOG (green) and GO (orange).

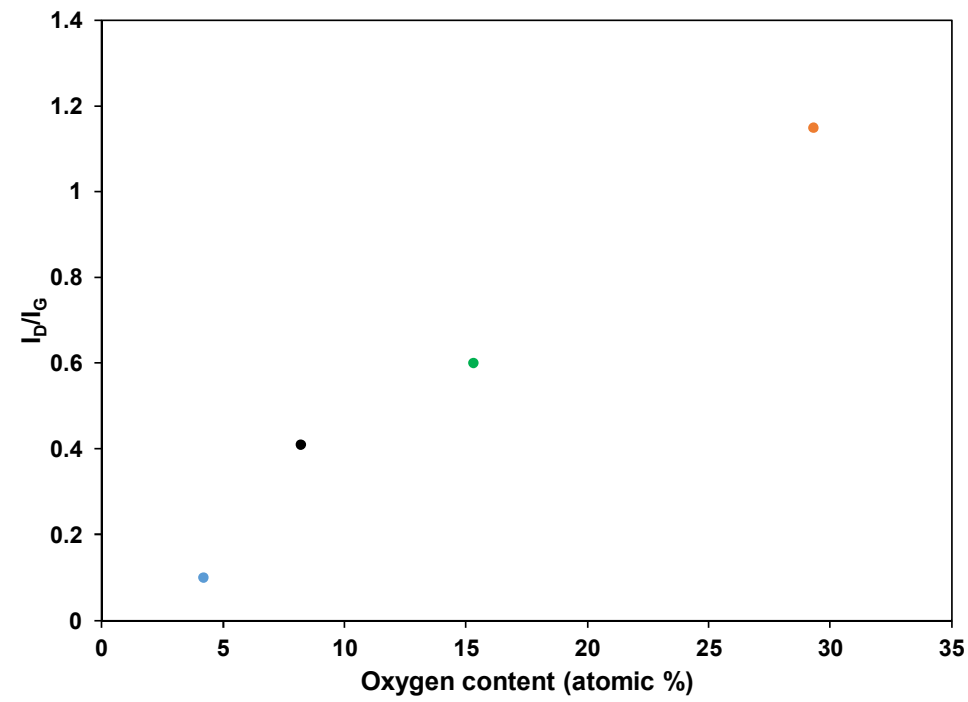

Fig. 6. Relationship between the $I_{D} / I_{G}$ ratios and oxygen content from XPS measurements for PG (blue), NAO (black), EOG (green) and GO (orange).

XPS data (Fig. 7) was further analyzed in order to reveal the differences between the powder samples in terms of five different chemical functionalities observed at 284.5, 285.0, 286.5, 287.9 and $289.2 \mathrm{eV}$, respectively. These signals can be assigned to $\mathrm{sp}^{2}$ carbon atoms in aromatic rings $(284.5 \mathrm{eV}), \mathrm{C}-\mathrm{C}$ and $\mathrm{C}-\mathrm{H}$ bonds $(285.0 \mathrm{eV}), \mathrm{C}$ atoms bonded to hydroxyl and 
ether $(\mathrm{C}-\mathrm{OH}, \mathrm{C}-\mathrm{O}-\mathrm{C}, 286.5 \mathrm{eV})$ and carbonyl $(>\mathrm{C}=\mathrm{O}, 287.9 \mathrm{eV})$ groups. Numerical values for the percent content of each are reported in Table 1. Based on these data, it was observed that GO was the only sample for which oxidation resulted in a significant reduction in the $\mathrm{C}=\mathrm{C}$ content and, as a consequence, an increase in $\mathrm{C}-\mathrm{C}$ bond content. As expected, the content of oxygenbased functional groups increased as $\mathrm{PG}<\mathrm{NAO}<\mathrm{EOG}<\mathrm{GO}$. Based on the TGA data, Raman spectra and oxygen content measurements, one may expect a stronger differentiation between the functional groups content of PG, NAO and EOG. However, it must be noted that XPS is a surface analytical technique, thus it may not be as sensitive as other, more aggressive analysis methods such as TGA.
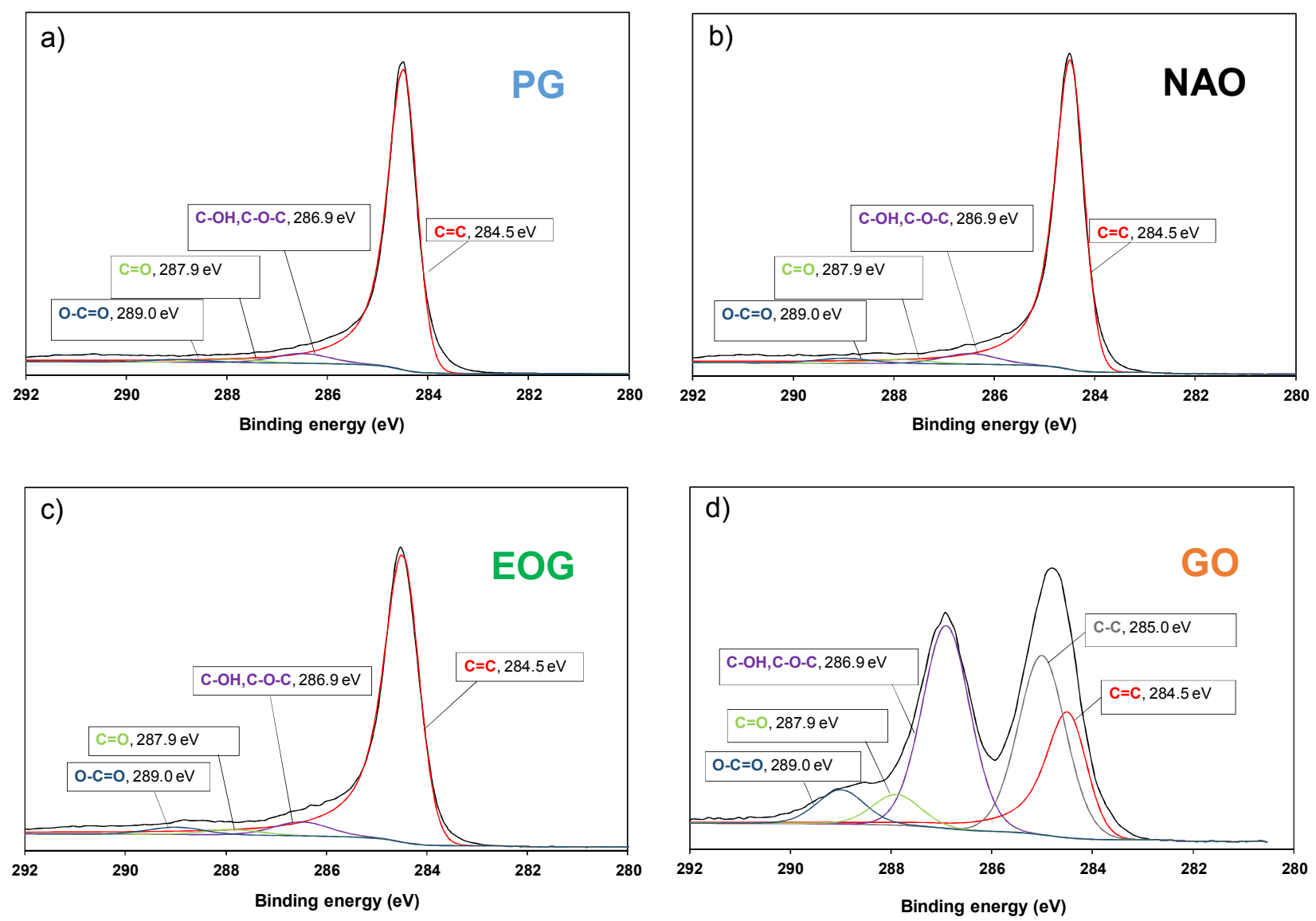

Fig. 7. XPS peak deconvolution for a) PG, b) NAO, c) EOG, and d) GO. 
Table 1. Surface functionalities determined by XPS (reported as $\%$ area).

\begin{tabular}{cccccc}
\hline & C=C & $\begin{array}{c}\text { C-C, } \\
\text { C-H }\end{array}$ & $\begin{array}{c}\text { C-OH, } \\
\text { C-O-C }\end{array}$ & $\left.\begin{array}{c}\text { C=O } \\
\text { PG }\end{array}\right)$ & O-C=O \\
NAO & 80.3 & 0 & 5.9 & 2.0 & 1.8 \\
EOG & 85.5 & 0 & 6.1 & 2.4 & 2.9 \\
GO & 18.4 & 32.8 & 37.1 & 5.5 & 6.2 \\
\hline
\end{tabular}

\section{Membrane preparation and characterization}

The powders described above were used to prepare 400 ppm water solutions, which were then deposited onto permeable nylon substrates using vacuum filtration. Thickness measurements were carried out independently with a micrometer and by Scanning Electron Microscopy (SEM) on a membrane cross section. The two distinct measurement techniques provided results in the same range (Fig. 8), and suggested that, when the particles have a higher oxygen content, the resulting membranes are thinner. This could be due to the fact that the presence of oxygen functionalities and, thus, localized defects, favored exfoliation during the sonication step carried out prior to film deposition, which would result in smaller particles and efficient particle packing during vacuum deposition. This was also observed in the SEM images in Fig. S2-S4, which showed some loose particles on the top layer of PG, NAO and EOG, as opposed to the fairly uniform and smooth surface of GO membranes (Fig. S5-S7). The GO membranes had a final thickness of about $10 \mu \mathrm{m}$, which was in agreement with results previously reported in the literature. ${ }^{11,30,34-35}$ 


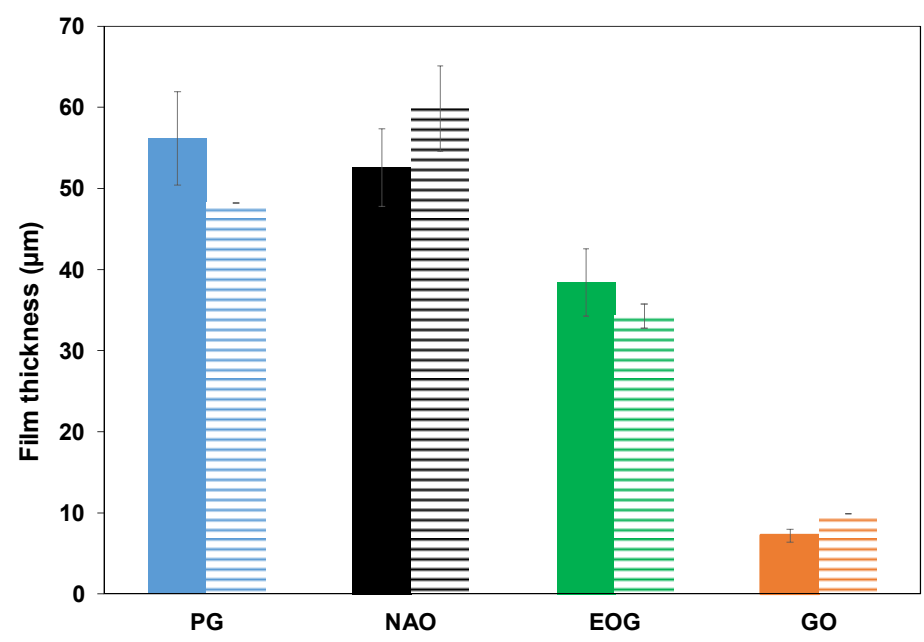

Fig. 8. Film thickness of membranes derived from PG, NAO, EOG and GO powder measured with a micrometer or by SEM imaging of a membrane cross section. Solid bars = micrometer results, striped bars $=$ SEM results. Error bars calculated from three replicates.

\section{Dye rejection}

Fig. 9 illustrates the structure of the three dyes employed in this study: a) Rhodamine B, b) Methyl Blue, and c) Congo Red. Rhodamine B is a cationic, highly fluorescent dye which find its most common uses as a fluorescence standard and in pigment formulations, for cell imaging or in analytical chemistry. ${ }^{36}$ Methyl blue, an anionic dye, is important for a number of biological and industrial applications. Its uses include microscopic staining, nucleic acids assay, controlled drug release and oral care. ${ }^{37}$ It is also used as an industrial colourant for paints, textiles, colour fiber, inks and highlighters and magnetic toners. ${ }^{37}$ Congo Red is an anionic diazo dye that exhibits $\mathrm{pH}$-sensitive behavior: it is red in alkaline solution and blue in acid solution and, for this reason, it is commonly used as an indicator and as a biological stain. ${ }^{38}$ Congo Red was also one of the first synthetic dyes heavily used in the textile industry. ${ }^{38}$ 


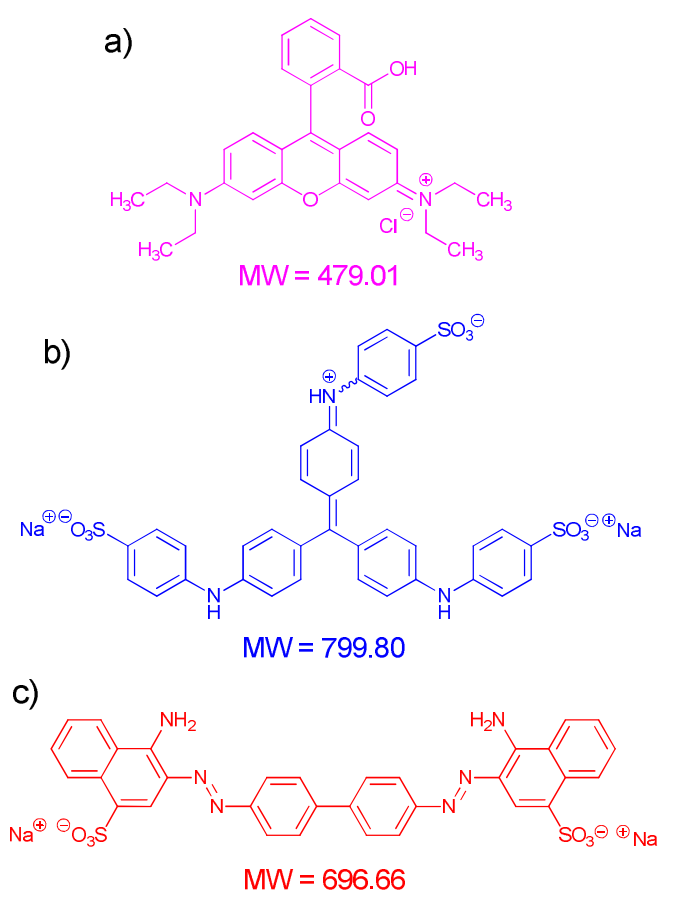

Fig. 9. Dyes employed for the rejection studies: a) Rhodamine B, b) Methyl Blue, and c) Congo Red.

The rejection of dyes by membranes derived from PG or oxidized graphite particles (Fig. 10 and S8-S10) could be due to one of three effects: 1) direct adsorption of dye molecules by the high surface area carbon particles, 2) electrostatic interactions between charged dyes and the functional groups of the membrane surface, and/or 3) physical sieving, which is controlled by channel sizes. The rejection behaviour was evaluated after several filtration cycles, to ensure saturation of adsorption sites. Thus, it was possible to evaluate the rejection characteristics of each membrane due to only effects 2) and 3).

When considering the rejection of the anionic dyes, Methyl Blue and Congo Red, no obvious trends emerged upon oxidation of the particles used to produce the membranes in this study. However, the behavior was different when the rejection of Rhodamine B (cationic dye) was studied. As the degree of oxidation, and thus the number of negative charges, of the 
membranes was increased their ability to reject Rhodamine $\mathrm{B}$ was also enhanced. This observation provides critical insight into future membrane design, whereby membrane oxidation may be used to tune the rejection of cationic molecules. Understanding dye rejection in the context of physical sieving was slightly more difficult. When examining the rejection data for the three dyes, no obvious correlation between the molecular weights of the dyes and their rejection were observed. For each membrane type, Congo Red rejection was most efficient. We attribute this behavior to Congo Red's propensity to aggregate in aqueous and organic solutions via $\pi-\pi$ stacking interactions. ${ }^{39,40}$ Thus, we postulate that Congo Red was rejected more efficiently due to the larger relative size of these aggregates in solution.

Despite the fact that GO-based membranes showed the highest rejection for Rhodamine B and Congo Red, EOG-based membranes showed a rejection of $87 \%$ for Congo Red. Thus, by combining the information regarding the physico-chemical properties (charge, aggregation, etc) of the dye or target molecule to be rejected and the properties of the membranes employed, partially oxidized graphite-based membranes may provide a valid replacement for those based on GO. Crucially, the use of such membranes would also circumvent the need for prolonged, harsh chemical oxidation methods (i.e., Hummers' method). 


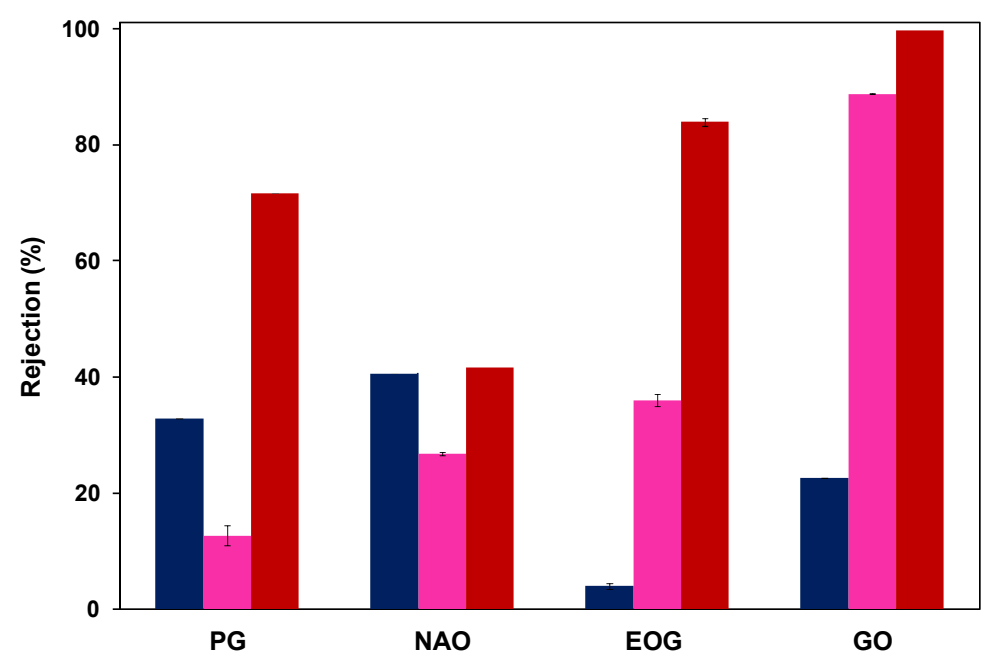

Fig. 10. Rejection of Methyl Blue (navy blue), Rhodamine B (pink) and Congo Red (red) dyes by membranes derived from PG, NAO, EOG and GO. Selected error bars calculated from three replicates.

The flux values, expressed in $\mathrm{L}$ per $\mathrm{m}^{2}$ of membrane area per $\mathrm{h}(\mathrm{LMH})$ and normalized with respect to the operating pressure in bar (LMH/bar, Fig. 11), for Rhodamine B were the highest amongst the tested dyes. The flux values for Methyl Blue were slightly lower, potentially relating to its higher molecular weight. In the case of Congo Red, the flux was significantly lower, possibly due to the obstruction of some membrane channels by dye molecule aggregates. GO membranes gave rise to the lowest flux values, potentially due to better particle packing (membranes other than GO present some loose powder on their surfaces and possibly have large channels between particles) and possible intercalation of GO sheets within the porous membrane (Fig. S5). It is therefore reasonable to assume that GO membranes should have lower permeability. 


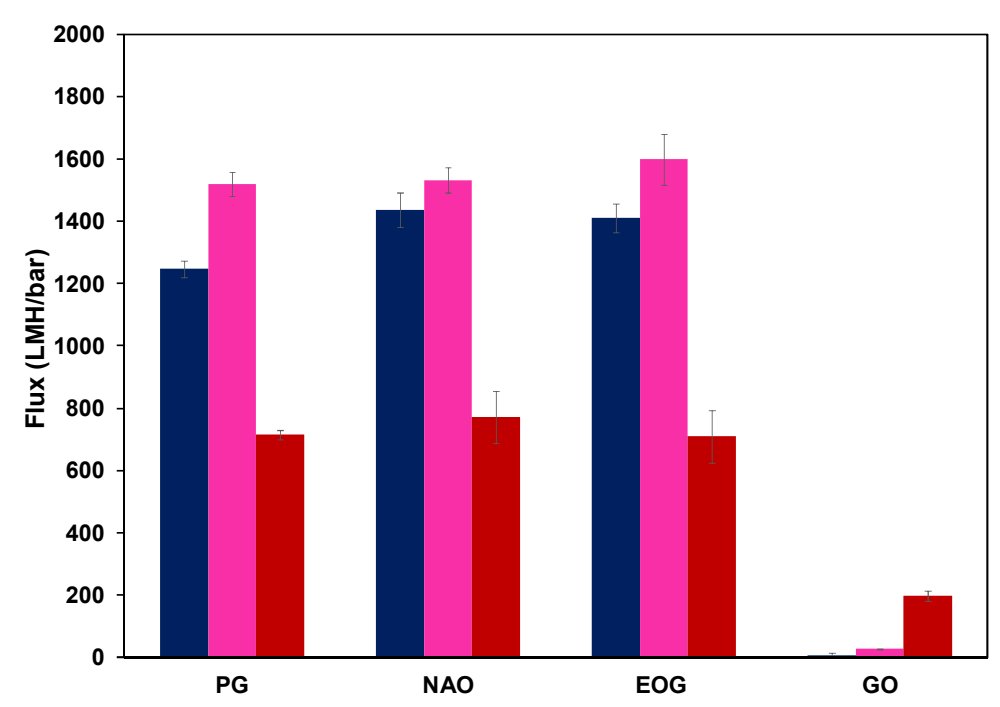

Fig. 11. Flux (LMH/bar) of Methyl Blue (navy blue), Rhodamine B (pink) and Congo Red (red) dyes by membranes derived from PG, NAO, EOG and GO. Error bars calculated from three replicates.

\section{Conclusions}

Graphite-derived particles with different degrees of oxidation were produced and their properties compared. An increasing degree of oxidation was correlated with an increase in the structural disorder of the graphite particles and more efficient packing of the particles when used to produce membranes. The resulting membranes were tested for the rejection of different types of organic dyes (Rhodamine B, Methyl Blue and Congo Red), and their rejection performance was explained in terms of both membrane and dyes characteristics. By combining this information, it was possible to find an alternative to GO-based membranes, such as the ones produced with EOG particles, which showed a rejection up to $87 \%$ for Congo Red. Moreover, the preparation of EOG is less time consuming, and the oxidation method used to produce EOG reduces the quantity of harsh chemicals used in the process and requires less washing steps than Hummers' 
method, presenting obvious manufacturing advantages and reduced environmental impact when compared to GO production.

\section{Acknowledgements}

The authors would like to acknowledge the Natural Science and Engineering Research Council (NSERC) of Canada (Engage, EGP 487122-15), Mitacs Accelerate (IT0622), the Canada Foundation for Innovation (JELF, 33977) and 3M Canada for funding this work. We thank Dr. Todd Simpson and Tim Goldhawk from the Western Nanofabrication Facility for assistance with SEM imaging, Dr. Paul Boyle and Aneta Borecki for assistance with PXRD measurements, and Catherine Bardeau and Jennifer Johnson from 3M Canada for assistance with EDX measurements.

\section{Supplementary material}

Supplementary data are available with the article through the journal Web site at \#\#\#\#\#\#\#.

\section{References}

(1) B. C. Group Water and Wastewater Treatment Technologies: Global Markets, 2013.

(2) Qu, X.; Alvarez, P. J. J.; Li, Q. Water Res. 2013, 47, 3931. doi: 10.1016/j.watres.2012.09.058.

(3) Park, S.; Ruoff, R. S. Nat. Nanotechnol. 2009, 4, 217. doi: 10.1038/nnano.2009.58.

(4) Liu, C.; Yu, Z.; Neff, D.; Zhamu, A.; Jang, B. Z. Nano Lett. 2010, 10, 4863. doi: $10.1021 / \mathrm{nl102661q}$.

(5) Chung, K.; Lee, C.-H.; Yi, G.-C. Science 2010, 330, 655. doi: 10.1126/science.1195403.

(6) Shao, Y.; Wang, J.; Wu, H.; Liu, J.; Aksay, I. A.; Lin, Y. Electroanal. 2010, 22, 1027. doi: 10.1002/elan.200900571. 
(7) Wang, G.; Shen, X.; Yao, J.; Park, J. Carbon 2009, 47, 2049. doi: 10.1016/j.carbon.2009.03.053.

(8) Zhang, L.; Shi, G. J. Phys. Chem. C 2011, 115, 17206. doi: 10.1021/jp204036a.

(9) Kumar, M.; Singh, K.; Dhawan, S. K.; Tharanikkarasu, K.; Chung, J. S.; Kong, B.-S.; Kim, E. J.; Hur, S. H. Chem. Eng. J. 2013, 231, 397. doi: 10.1016/j.cej.2013.07.043.

(10) Gao, W.; Majumder, M.; Alemany, L. B.; Narayanan, T. N.; Ibarra, M. A.; Pradhan, B. K.; Ajayan, P. M. ACS Appl. Mater. Interfaces 2011, 3, 1821. doi: 10.1021/am200300u.

(11) Joshi, R. K.; Carbone, P.; Wang, F. C.; Kravets, V. G.; Su, Y.; Grigorieva, I. V.; Wu, H. A.; Geim, A. K.; Nair, R. R. Science 2014, 343, 752. doi: 10.1126/science.1245711.

(12) Chen, D.; Feng, H.; Li, J. Chem. Rev. 2012, 112, 6027. doi: 10.1021/cr300115g.

(13) Hung, W.-S.; Tsou, C.-H.; De Guzman, M.; An, Q.-F.; Liu, Y.-L.; Zhang, Y.-M.; Hu, C.C.; Lee, K.-R.; Lai, J.-Y. Chem. Mater. 2014, 26, 2983. doi: 10.1021/cm5007873.

(14) Han, Y.; Jiang, Y.; Gao, C. ACS Appl. Mater. Interfaces 2015, 7, 8147. doi: 10.1021/acsami.5b00986.

(15) Zhang, J.; Xu, Z.; Shan, M.; Zhou, B.; Li, Y.; Li, B.; Niu, J.; Qian, X. J. Membr. Sci. 2013, 448, 81. doi: 10.1016/j.memsci.2013.07.064.

(16) Zhao, C.; Xu, X.; Chen, J.; Yang, F. Desalination 2014, 334, 17. doi: 10.1016/j.desal.2013.07.011.

(17) Kim, S. G.; Hyeon, D. H.; Chun, J. H.; Chun, B.-H.; Kim, S. H. Desalin. Water Treat. 2013, 51, 6338. doi: 10.1080/19443994.2013.780994.

(18) Gao, Y.; Hu, M.; Mi, B. J. Membr. Sci. 2014, 455, 349. doi: 10.1016/j.memsci.2014.01.011.

(19) Hummers, W. S.; Offeman, R. E. J. Am. Chem. Soc. 1958, 80, 1339. doi: 10.1021/ja01539a017. 
(20) Jeon, I.-Y.; Shin, Y.-R.; Sohn, G.-J.; Choi, H.-J.; Bae, S.-Y.; Mahmood, J.; Jung, S.-M.;

Seo, J.-M.; Kim, M.-J.; Wook Chang, D.; Dai, L.; Baek, J.-B. Proc. Natl. Acad. Sci. U.S.A. 2012, 109, 5588. doi: 10.1073/pnas.1116897109.

(21) Bai, M.; Chen, J.; Wu, W.; Zeng, X.; Wang, J.; Zou, H. Colloids Surf. A Physicochem. Eng. Asp. 2016, 490, 59. doi: 10.1016/j.colsurfa.2015.11.033.

(22) Wei, L.; Wu, F.; Shi, D.; Hu, C.; Li, X.; Yuan, W.; Wang, J.; Zhao, J.; Geng, H.; Wei, H.; Wang, Y.; Hu, N.; Zhang, Y. Sci. Rep. 2013, 3, 2636. doi: 10.1038/srep02636.

(23) Rambabu, N.; Azargohar, R.; Dalai, A. K.; Adjaye, J. Fuel Process. Technol. 2013, 106, 501. doi: 10.1016/j.fuproc.2012.09.019.

(24) Zacharia, R. Doctoral dissertation, Freie Universität Berlin, 2004.

(25) Abdolhosseinzadeh, S.; Asgharzadeh, H.; Seop Kim, H. Sci. Rep. 2015, 5, 10160. doi: $10.1038 / \operatorname{srep} 10160$.

(26) Song, J.; Wang, X.; Chang, C.-T. J. Nanomater. 2014, 2014, 6. doi: 10.1155/2014/276143.

(27) Spyrou, K.; Rudolf, P. In Functionalization of Graphene; Wiley-VCH Verlag GmbH \& Co. KGaA: Weinham, 2014.

(28) Girgis, B. S.; Temerk, Y. M.; Gadelrab, M. M.; Abdullah, I. D. Carbon Lett. 2007, 8, 95. doi: 10.5714/CL.2007.8.2.095.

(29) Kosynkin, D. V.; Higginbotham, A. L.; Sinitskii, A.; Lomeda, J. R.; Dimiev, A.; Price, B. K.; Tour, J. M. Nature 2009, 458, 872. doi: 10.1038/nature07872.

(30) Nair, R. R.; Wu, H. A.; Jayaram, P. N.; Grigorieva, I. V.; Geim, A. K. Science 2012, 335, 442. doi: $10.1126 /$ science. 1211694 .

(31) Pham, V. H.; Cuong, T. V.; Hur, S. H.; Oh, E.; Kim, E. J.; Shin, E. W.; Chung, J. S. J. Mater. Chem. 2011, 21, 3371. doi: 10.1039/C0JM02790A. 
(32) Pimenta, M.; Dresselhaus, G.; Dresselhaus, M. S.; Cancado, L.; Jorio, A.; Saito, R. Phys. Chem. Chem. Phys. 2007, 9, 1276. doi: 10.1039/B613962K.

(33) Zhao, J.; Liu, L.; Li, F., Ed. Graphene Oxide: Physics and Applications; Springer-Verlag: Berlin, 2014.

(34) Coleman, M.; Tang, X. Nano Res. 2015, 8, 1128. doi: 10.1007/s12274-014-0593-x.

(35) Hung, W.-S.; An, Q.-F.; De Guzman, M.; Lin, H.-Y.; Huang, S.-H.; Liu, W.-R.; Hu, C.-C.; Lee, K.-R.; Lai, J.-Y. Carbon 2014, 68, 670. doi: 10.1016/j.carbon.2013.11.048.

(36) Beija, M.; Afonso, C. A. M.; Martinho, J. M. G. Chem. Soc. Rev. 2009, 38, 2410. doi: 10.1039/B901612K.

(37) Sharma, P.; Hussain, N.; Borah, D. J.; Das, M. R. J. Chem. Eng. Data 2013, 58, 3477. doi: $10.1021 / \mathrm{je} 400743 \mathrm{r}$.

(38) Steensma, D. P. Arch. Path. Lab. Med. 2001, 125, 250. doi: 10.1043/00039985(2001)125<0250:CR>2.0.CO;2.

(39) Frid, P.; Anisimov, S. V.; Popovic, N. Brain Res. Rev. 2007, 53, 135. doi: 10.1016/j.brainresrev.2006.08.001.

(40) Stopa, B.; Jagusiak, A.; Konieczny, L.; Piekarska, B.; Rybarska, J.; Zemanek, G.; Król, M.; Piwowar, P.; Roterman, I. J. Mol. Model. 2013, 19, 4731. doi: 10.1007/s00894-012-1744-1. 